\title{
Use of Colonoscopy as a Primary Screening Test for Colorectal Cancer in Average Risk People
}

Maite Betés, M.D., Ph.D., Miguel A. Muñoz-Navas, M.D., Ph.D., José M. Duque, M.D., Ph.D., Ramón Angós, M.D., Ph.D., Elena Macías, M.D., Jose C. Súbtil, M.D., Ph.D., Maite Herraiz, M.D., Susana De La Riva, M.D., Miguel Delgado-Rodríguez, M.D., M.P.H., and Miguel A. Martínez-González, M.D., M.P.H.

Department of Gastroenterology, University Clinic, University of Navarra, Pamplona, Spain; Department of Epidemiology and Public Health, School of Medicine, University of Navarra, Pamplona; and Division of Preventive Medicine, University of Jaén, Jaén, Spain

\section{OBJECTIVE}

The use of colonoscopy as a primary screening test for colorectal cancer (CRC) in average risk adults is a subject of controversy. Our primary objective was to build a predictive model based on a few simple variables that could be used as a guide for identifying average risk adults more suitable for examination with colonoscopy as a primary screening test.

\section{METHODS}

The prevalence of advanced adenomas was assessed by primary screening colonoscopy in 2210 consecutive adults at least $40 \mathrm{yr}$ old, without known risk factors for CRC. Age, gender, and clinical and biochemical data were compared among people without adenomas, those with nonadvanced adenomas, and those with any advanced neoplasm. A combined score to assess the risk of advanced adenomas was built with the variables selected by multiple logistic regression analysis.

\section{RESULTS}

Neoplastic lesions were found in 617 subjects (27.9\%), including 259 with at least one neoplasm that was $10 \mathrm{~mm}$ or larger, villous, or with moderate-to-severe dysplasia, and 11 with invasive cancers. Advanced lesions were more frequent among men, older people, and those with a higher body mass index (BMI). These three variables were independent predictors of advanced adenomas in multivariate analysis. A score combining age, sex, and BMI was developed as a guide for identifying individuals more suitable for screening colonoscopy.

\section{CONCLUSIONS}

Age, gender, and BMI can be used to build a simple score to select those average risk adults who might be candidates for primary screening colonoscopy.

Reprint requests and correspondence: Maria Teresa Betés Ibáñez, M.D. Departamento de Digestivo, Clínica Universitaria de Navarra 31080 Pamplona, Spain. 


\section{INTRODUCTION}

Colorectal cancer (CRC) is the second most frequent cause of cancer-related death in western countries (1). Most cancers develop from benign adenomatous polyps (2, 3), in subjects with no known risk factors for the disease (4). Although it is not yet possible to determine which adenomas will progress to cancer, certain pathological features have been found to correlate with the risk of progressing to $\operatorname{CRC}(3,5)$. "Advanced adenomas" have been defined as those with at least one of the following characteristics: size $1 \mathrm{~cm}$ or larger, tubulovillous or villous histology, and moderate or severe dysplasia $(6-9)$.

Screening with full colonoscopy as a primary procedure has been limited to a few small series (10-16), and results have not been focused in advanced adenomas. Two large colonoscopic series recently published $(17,18)$ have assessed the proportion of advanced proximal adenomas in average risk adults. Although the prevalence of colonic adenomas is higher among men than among women $(5,12,19,20)$ and increases with age $(11,13,15)$, more data are needed to adequately assess the independent role of the most relevant predictors of advanced adenomas (18). A variety of factors have been linked to the development of adenomas or CRC (21-25), but currently there is no dominant risk factor that could be practically used for risk stratification in screening for neoplasia among average risk adults without known family history of CRC. Abdominal symptoms with no evidence of bleeding have been considered a poor indication for colonoscopy in series with small numbers of patients (26-29). Clarification of the relative impact of these and other variables on the risk of advanced adenomas in average risk persons is needed, because such clarification might provide basis to design more efficient CRC screening strategies.

We performed total colonoscopy in a large series of average risk subjects without any symptoms suggesting colonic neoplasm, to establish the prevalence of advanced adenomas and to analyze which clinical and biochemical data could predict their presence in these patients. Our primary objective was to build a predictive model based on a few simple variables which, having significant associations with the presence of advanced neoplasms, could at the same time be easily obtained for each patient. This model could be used as a guide for identifying adults more suitable for examination with colonoscopy as a primary screening test.

\section{MATERIALS AND METHODS}

\section{Study Design}

From 1988 to 1998, full colonoscopy was performed as a primary screening procedure in all consecutive patients $40 \mathrm{yr}$ of age or older, without family history of CRC or any symptom suggesting colonic neoplasm, who were referred to our endoscopy unit for CRC screening. The study protocol was approved by a central human-rights committee, and written informed consent was obtained in all cases.

Patients were recruited in one of two ways: 1) if they came for a routine health checkup, or 2) if they were attending medical clinics for follow-up of stable medical problems. All the patients provided a routine medical history and underwent physical examination before the colonoscopy. Clinical and biochemical data were recorded as 
shown in Table 1. Body mass index (BMI: weight in kilograms/squared height in meters) was used to measure body fat.

Any subject who underwent colonoscopy but had reported hematochezia, a change in bowel habit, development of persistent abdominal or rectal pain (in the year before colonoscopy) was excluded. Other exclusion criteria were iron deficiency anemia, weight loss, previous colon polyps or cancer, any first degree relative(s) with colon cancer, previous breast or uterine cancer, inflammatory bowel disease, previous abdominal radiation, colonoscopy or barium enema within $5 \mathrm{yr}$ performed for any indication, and use of anticoagulants. Subjects who had an incomplete colonoscopy were excluded from the analysis. Fecal occult blood testing was not performed before colonoscopic screening.

Patients were prepared for colonoscopy by administration of PEG-electrolyte GI lavage or oral phosphosoda. Colonos-copies were performed by staff gastroenterologists or gastroenterology fellows under the supervision of a staff gastroenterologist, with the Olympus CF-V10L, CF-100HL, CF-130L, or CFQ-140L (Olympus Europa, Barcelona, Spain) colonoscopes. Meperidine plus midazolam or propofol were used as needed for sedation. All polyps were removed with standard polypectomy snares.

The following endoscopic findings were assessed: 1) location of each colorectal neoplasm (cancer or polyp) according to the distance from the anal verge, as measured with markings on the endoscope, and 2) size of each polyp (when seen intact or first removed).

Standard methods were used for histologic assessment, with all polyps fixed in $10 \%$ formol saline, totally embedded, and routinely stained with hematoxylin and eosin (30, 31 ), and were diagnosed according to the criteria of the World Health Organization by pathologists with a special expertise in GI pathology. Dysplasia was graded as mild, moderate, or severe (32). Patients with intramucosal carcinoma or carcinoma in situ were classified as having severe dysplasia (30). CRC was defined as the invasion of malignant cells beyond the muscularis mucosa.

Patients with multiple adenomas were categorized according to the largest tumor diameter, the most villous histology, and the most severe grade of dysplasia.

To make our data comparable with other studies $(6-9,15,17)$, we considered two definitions of "advanced adenoma": 1) "broad definition," if any of the following criteria were fulfilled for any adenoma: size $1 \mathrm{~cm}$ or larger, villous (or tubulovillous) histology, and moderate or severe grade of dysplasia; and 2) "restricted definition" in which moderate dysplasia was excluded (i.e., only severe dysplasia was considered).

\section{Statistical Analysis}

We compared clinical and biochemical data of patients with no adenomas, patients with nonadvanced adenomas, and patients with at least one advanced colonic adenoma. Chisquared test for linear trend and one-way analysis of variance were used for between-group comparisons. A $\mathrm{p}$ value of less than 0.05 was considered statistically significant. Multiple logistic regression was used to identify independent predictors of advanced adenomas. Two different logistic regression models were constructed, depending on the criteria for advanced lesion ("broad" or "restricted" criteria, see above) used as the dependent variable. 
The independent variables were selected according to the purposeful method (33). Initial candidate variables were those withp $<0.25$ in the univariate analysis. We examined whether there was any significant interaction (effect modification) between every two independent variables included in multivariate analysis.

A receiver operating characteristic (ROC) plot was constructed, and the area under the curve was estimated to assess the degree of discrimination provided by the model (34).

To predict the presence of advanced neoplasms in a given individual, a diagnostic score was designed with the independent variables selected by the multivariate analysis. Continuous variables were converted into categoric variables. A new logistic regression model was run with these transformed variables. The coefficients yielded by the model were rounded to the nearest half integer and then multiplied by 2 to avoid decimals. A score for each subject was computed. The validity of the score was assessed by ROC analysis.

\section{RESULTS}

\section{Characteristics of Patients With and Without Advanced Adenomas}

From 1988 to 1998,2260 consecutive average risk persons underwent primary colonoscopic screening. Colonoscopy was completed to cecum in 2210 patients (97.8\%), who were included in our analysis. Characteristics of the study population are shown in Table 1. Their mean age was $57.9 \mathrm{yr}(\mathrm{SD}=8.6) ; 74.6 \%$ were men.

Patients were classified on the basis of the most advanced lesion (Table 2). No polypoid lesions were found in 1385 patients (62.7\%). Among the other 825 (37.3\%), 2210 polyps were removed. Six hundred seventeen patients $(27.9 \%)$ had adenomas of any type or invasive cancer. Advanced disease (defined as an adenoma $10 \mathrm{~mm}$ or larger, or with villous features, moderate-to-severe dysplasia, or invasive cancer) was present in 259 patients $(11.7 \%)$. In $54(2.4 \%)$ the most advanced lesion were tubular adenomas 10 $\mathrm{mm}$ or larger. Ninety patients $(4.0 \%)$ had adenomas with villous features, $153(6.9 \%)$ had adenomas with moderate dysplasia, and 27 (1.2\%) had adenomas with severe dysplasia or invasive cancer. Among the 11 patients with invasive cancer (mean age $66.6 \mathrm{yr} ; 10$ male), the stage was T1N0 in four, T2N0 in two, and T3N0 in three; two patients had nodal involvement, and none had metastatic disease. Five patients had cancers proximal to the splenic flexure.

When moderate dysplasia was accepted as a criterion for "advanced lesion" (Table 3), 68 patients $(26.3 \%)$ had advanced lesions only in the proximal colon, $137(52.9 \%)$ had advanced disease only in the distal colon (i.e., distal to the splenic flexure), and 54 $(20.8 \%)$ had advanced neoplasms in both the distal and the proximal colon. When the "restricted" definition for advanced adenoma was applied (Table 3), 37 patients (23.7\%) had advanced lesions only in the proximal colon, 100 had advanced disease only in the distal colon (64.1\%), and $19(12.2 \%)$ presented advanced neoplasms in both colonic segments.

Comparisons of clinical and biochemical data of patients according to the existence and severity colonic adenomas are shown in Table 4 . Nonadvanced adenomas were found in $18.4 \%$ of men but only in $9.8 \%$ of women. Advanced adenomas were also more likely to be present in men than in women $(13.5 \%$ vs $6.6 \%)$. 
Persons with adenomas were significantly older than those without adenomas (59.8 vs $57.2 \mathrm{yr}$ ), and patients with advanced lesions were significantly older than those with nonadvanced neoplasms. Adenomas were associated with a significantly higher mean BMI (27.4 vs $26.9 \mathrm{~kg} / \mathrm{m} 2)$. Patients with advanced lesions also had a significantly higher BMI than those with nonadvanced adenomas. Mean cholesterol levels were significantly higher among persons with adenomas than among those without adenomas ( $234.8 \mathrm{vs} 228.3 \mathrm{mg} / \mathrm{dl})$, but no significant differences were found in nonadvanced versus advanced lesions. There were no differences in the rates of adenomas according to the form of recruitment, the presence of nonspecific GI symptoms, bowel habit, daily consumption of nonsteroidal anti-inflammatory drugs, or triglycerides serum levels. Similar results were found when we considered the "restricted" criteria for advanced adenoma (data not shown).

\section{Analysis of Predictive Factors Associated With Advanced Adenomas in Average Risk Persons}

In univariate analysis, older age, male sex, and higher BMI were significantly associated with a higher probability of advanced adenoma. In the multivariate logistic regression model, age, sex, and BMI were shown to be significantly and independently associated with advanced lesions (Table 5). The prevalence of advanced adenomas increased monotonically with age. When age was introduced as a continuous variable, the adjusted OR was $1.05(95 \%$ CI $=1.03-1.07)$ for both definitions of advanced adenomas (data not shown). Male sex was associated with a significantly higher risk of advanced adenomas after adjusting for the other variables in the model (OR $=2.08$ for the broad definition and $\mathrm{OR}=3.64$ for the restricted definition). The risk of advanced adenomas significantly increased with a higher BMI (adjusted OR for BMI $>30 \mathrm{~kg} / \mathrm{m}^{2}$ $=2.08$ for the broad definition and 1.78 for the restricted definition). The adjusted ORs for BMI as a continuous variable were 1.06 and 1.04 (broad and restricted definitions, respectively).

We also examined the interaction between every two independent variables included in the multivariate analyses. None of them showed statistical significance. A score was designed as follows. Gender, BMI, and age (the latter two as continuous variables) were selected by a stepwise procedure. BMI and age were converted into categoric variables. BMI was grouped in 10-point categories $(<-25,26-35$, and $>35 \mathrm{~kg} / \mathrm{m} 2)$. Age was grouped into decades. A new logistic regression model was run with these transformed variables. The coefficients yielded by the model were rounded to the nearest half integer ( 0.8 was rounded to 1 and 0.6 to 0.5 ) and then multiplied by 2 to avoid decimals. The coefficients in the model were $0.76,0.46$, and 0.41 for sex, BMI, and age, respectively. Therefore, to be male received 2 points (female $=0$ ); each $10 \mathrm{~kg} / \mathrm{m} 2$ above 25 in BMI received 1 point, and the same was applied for each decade above $50 \mathrm{yr}$ (Table 6).

The validity of the score was assessed by ROC analysis. The areas under the ROC curve with the logistic models including the original variables were $65.37 \%$ and $67.24 \%$ for both the broad and the restricted criteria used to define advanced adenoma, respectively. The loss of validity with the transformed variables was negligible (approximately $1 \%$ ).

With higher score, the number of persons who should undergo colonoscopic screening to detect at least one advanced lesion progressively decreased, as shown in Table 7. 


\section{DISCUSSION}

We found that age, gender, and BMI are independent predictors of the risk of advanced adenoma in average risk adults, although their predictive value is low. Nevertheless, in the absence of better predictors, these variables, which can be easily obtained, might help in the selection of more suitable candidates for primary screening colonoscopy.

Most small simple tubular adenomas do not progress to cancer (35). However, adenomas with advanced features have been consistently shown to exhibit a greater risk of malignant transformation (5). Although adenomas with moderate dysplasia have a risk of malignant transformation higher than adenomas with only mild dysplasia (5), this characteristic is not considered a feature of advanced adenoma for all authors (6-9, $15,17,18,36)$; therefore, we have considered two definitions of advanced adenoma, depending on the inclusion or not of moderate dysplasia as a feature of advanced lesion.

Few studies have evaluated variables associated with the presence of advanced colonic adenomas in average risk, asymptomatic adults, and limited clinical information is available to supplement the findings provided by the screening examinations. Advanced disease was present in $11.7 \%$ in our series $(7.0 \%$ if we considered the restricted definition for advanced adenoma), a percentage similar to that found in a recent large series in the United States (17). To better establish the yield of colonoscopy as a primary screening procedure, fecal occult blood testing was not performed before endoscopic examination. We carefully screened the subjects included in our analysis to ensure that they have neither family history of CRC nor any symptom suggesting high risk status. In fact, the prevalence of polyps was unrelated to several other clinical variables included in the analyses. Patients with nonspecific abdominal symptoms had similar rates of advanced adenomas as asymptomatic patients $(10.9 \%$ vs $12.2 \%, p=$ $0.34)$, as reported in some small studies and a recent large series $(26-29,37,38)$, and there were no differences according to the method used to recruit patients $(p=0.88)$. Altered bowel habit was not a predictor of advanced adenoma in our series. Therefore, the prevalence of significant lesions in this population largely reflects the background prevalence in asymptomatic populations.

Information on the prevalence of advanced adenomas by age and gender is limited; one autopsy series reported a prevalence of large polyps of $4.6 \%$ at age greater than $54 \mathrm{yr}$ and $15.6 \%$ at $75 \mathrm{yr}$ (39). Rex et al. (13) reported that $15 \%$ of asymptomatic men and $7 \%$ of women aged $60 \mathrm{yr}$ or older had advanced colorectal neoplasms. Similar percentages had been found in small clinical series and autopsy studies $(11,12,14,40-42)$. We found a linear association between age and the prevalence of advanced colonic neoplasia. The higher yield of screening colonoscopy in men is consistent with recent reports that $\mathrm{CRC}$ incidence and mortality are now approximately 1.6-fold greater in men than in women (43).

In our series, BMI at screening colonoscopy was an independent predictor of advanced adenomas. Studies of obesity and colorectal polyps have presented somewhat conflicting findings $(22,24,44-47)$. Approximately half of them show a positive association between BMI or some other anthropometric measures and large-bowel polyps $(24,44,45)$. In a recent study, current BMI, the net amount of weight gained during the $10 \mathrm{yr}$ before sigmoidoscopy, and the number of large weight changes during adulthood were independently associated with colorectal adenomas (48). To our knowledge, this is the first report that analyzes BMI as an independent risk factor for 
advanced adenomas in a large population undergoing primary colonoscopic screening. Obesity might be a marker for one or more risk factors for CRC. Body weight is largely a function of the net effects of energy expenditure and energy intake. Given the difficulty of measuring both physical activity and dietary intake accurately, BMI could represent a more practical method of determining the cumulative effects of these two variables.

A limitation of this study should be emphasized: our sample was biased toward persons with medium-to-high socioeconomic status, interested in undergoing CRC screening. However, none of these factors is acknowledged as a major determinant of the incidence of colorectal neoplasms.

Our data might provide guidance regarding population strategies for CRC screening, as well as ground for discussing relative risks with individual patients in clinical settings. Population screening colonoscopy for certain subgroups of average risk persons, such as men (particularly obese) older than $60 \mathrm{yr}$, would produce a substantial yield of lesions at increased risk for the subsequent development of CRC.

\section{ACKNOWLEDGMENTS}

The authors thank Elena Santamaría, Cristina Carretero, and the GI staff of the University Clinic of Navarra for their assistance in conducting this study.

\section{REFERENCES}

1. Parkin DM, Pisani P, Ferlay J. Global cancer statistics. CA Cancer J Clin 1999;49:33-64.

2. Winawer SJ, Zauber AG, Ho MN, et al. Prevention of colo-rectal cancer by colonoscopic polypectomy. The National Polyp Study Workgroup. N Engl J Med 1993;329:1977-81.

3. Muto T, Bussey HJR, Morson BC. The evolution of cancer of the colon and rectum. Cancer 1975;36:2251-70.

4. Burt RW, Bishop DT, Lynch HT, et al. Risk and surveillance of individuals with heritable factors for colorectal cancer. Bull WHO 1990;68:655-65.

5. Atkin WS, Morson BC, Cuzick J. Long-term risk of colorectal cancer after excision of rectosigmoid adenomas. N Engl J Med 1992;326:658-62.

6. Levin TR, Palitz A, Grossman S, et al. Predicting advanced proximal colonic neoplasia with screening sigmoidoscopy. JAMA 1999;281:1611-7.

7. Read TE, Read JD, Butterly LF. Importance of adenomas $5 \mathrm{~mm}$ or less in diameter that are detected by sigmoidoscopy. N Engl J Med 1997;336:8-12.

8. Wallace MB, Kemp JA, Trnka YM, et al. Is colonoscopy indicated for small adenomas found by screening flexible sigmoidoscopy? Ann Intern Med 1998;129:273-8.

9. Schoen RE, Corle D, Cranston L, et al. The Polyp Prevention Trial. Is colonoscopy needed for the nonadvanced adenoma found on sigmoidoscopy? Gastroenterology 1998;115:533-41.

10. Rex DK, Lehman GA, Hawes RH, et al. Screening colonoscopy in asymptomatic average-risk persons with negative fecal occult blood tests. Gastroenterology 1991;100:64-7. 
11. Lieberman DA, Smith FW. Screening for colon malignancy with colonoscopy. Am J Gastroenterol 1991;86:946-51.

12. Johnson DA, Gurney MS, Volpe RJ, et al. A prospective study of the prevalence of colonic neoplasms in asymptomatic patients with an age-related risk. Am J Gastroenterol 1990;85: 969-74.

13. Rex DK, Lehman GA, Ulbright TM, et al. Colonic neoplasia in asymptomatic persons with negative fecal occult blood tests: Influence of age, gender, and family history. Am J Gastroenterol 1993;88:825-31.

14. Foutch PG, Mai H, Pardy K, et al. Flexible sigmoidoscopy may be ineffective for secondary prevention of colorectal cancer in asymptomatic, average-risk men. Dig Dis Sci 1991; 36:924-8.

15. DiSario JA, Foutch PG, Mai HD, et al. Prevalence and malignant potential of colorectal polyps in asymptomatic, average-risk men. Am J Gastroenterol 1991;86:941-5.

16. Guillem JG, Forde KA, Treat MR, et al. Colonoscopic screening for neoplasms in asymptomatic first-degree relatives of colon cancer patients. Dis Colon Rectum 1992;35:523-9.

17. Lieberman DA, Weiss DG, Bond JH, et al. Veterans Affairs Cooperative Study Group. Use of colonoscopy to screen asymptomatic adults for colorectal cancer. N Engl J Med 2000;343:162-8.

18. Imperiale TF, Wagner DR, Lin CY, et al. Risk of advanced proximal neoplasms in asymptomatic adults according to the distal colorectal findings. N Engl J Med 2000;343:169-74.

19. Bombi JA. Polyps of the colon in Barcelona, Spain. An autopsy study. Cancer 1988;61:1472-6.

20. Rickert RR, Auerbach O, Garfinkel L, et al. Adenomatous lesions of the large bowel: An autopsy survey. Cancer 1979; 43:1847-57.

21. Giovannucci E, Stampfer MJ, Colditz GA, et al. Relationship of diet to risk of colorectal adenoma in men. Am J Epidemiol 1990;132:783.

22. Mannes GA, Maier A, Thieme C, et al. Relation between the frequency of colorectal adenoma and the serum cholesterol level. $N$ Engl $J$ Med 1986;315:1634-8.

23. Kikendall JW, Bowen PE, Burgess MB, et al. Cigarettes and alcohol as independent risk factors for colonic adenomas. Gastroenterology 1989;97:660-4.

24. Neugut AI, Lee WC, Garbowski GC, et al. Obesity and colo-rectal adenomatous polyps. J Natl Cancer Inst 1991;83:359- 61.

25. Slattery ML, Schumacher MC, Smith KR, et al. Physical activity, diet, and risk of colon cancer in Utah. Am J Epidemiol 1988;128:989-9.

26. Berkowitz I, Kaplan M. Indications for colonoscopy. An analysis based on indications and diagnostic yield. S Afr Med J 1993;83:245-8.

27. Brenna E, Skreden K, Waldum HL, et al. The benefit of colonoscopy. Scand J Gastroenterol 1990;25:81-8.

28. Neugut AI, Garbowski GC, Waye JD, et al. Diagnostic yield of colorectal neoplasia with the use of colonoscopy for abdominal pain, change in bowel habits, and rectal bleeding. Am J Gastroenterol 1993;88:1179-84.

29. Rex DK, Lehman GA, Mark D, et al. Colonoscopy vs sigmoidoscopy/ACBE for colonic evaluation of symptomatic patients without evidence ofbleeding. Gastrointest Endosc 1993; 39:302 (abstract).

30. O'Brien MJ, Winawer SJ, Zauber AG, et al. The National Polyp Study. Patient and polyp characteristics associated with high-grade dysplasia in colorectal adenomas. Gastroenterology 1990;98:371-9. 
31. Morson BC, Dawson IMP, Day DW. et al. Benign epithelial tumours and polyps. In: Morson BC, Dawson IMP, eds. Gastrointestinal pathology. Oxford: Blackwell Scientific, 1991: 563-96.

32. Konishi F, Morson BC. Pathology of colorectal adenomas: A colonoscopic survey. J Clin Pathol 1982;35:830-41.

33. Hosmer DW, Lemeshow S. Applied logistic regression. New York: John Willey \& Sons, 1989.

34. Hanley JA, McNeil BJ. The meaning and use of the area under a Receiver Operating Characteristic (ROC) curve. Radiology 1992;143:29-36.

35. Bersentes K, Fennerty MB, Sampliner RE, et al. Lack of spontaneous regression of tubular adenomas in two years of follow-up. Am J Gastroenterol 1997;92:1117-20.

36. Gaglia P, Atkin WS, Whitelaw S, et al. Variables associated with the risk of colorectal adenomas in asymptomatic patients with a family history of colorectal cancer. Gut 1995;36:385-90.

37. Lieberman DA, De Garmo PL, Fleischer DE, et al. Colonic neoplasia in patients with nonspecific GI symptoms. Gastrointest Endosc 2000;51:647-51.

38. Longo WE, Dean PA, Virgo KS, et al. Colonoscopy in patients with benign anorectal disease. Dis Colon Rectum 1993;36: 368-71.

39. Winawer SJ, Fletcher RH, Miller L, et al. Colorectal cancer screening. Clinical guidelines and rationale. Gastroenterology 1997;112:594-642.

40. Cannon-Albright LA, Skolnick MH, Bishop DT, et al. Common inheritance of susceptibility to colonic adenomatous polyps and associated colorectal cancers. N Engl J Med 1988; 319:533-7.

41. Lanspa SJ, Lynch HT, Smyrk TC, et al. Colorectal adenomas in the Lynch syndromes. Results of a colonoscopy screening program. Gastroenterology 1990;98:1117-22.

42. Love RR, Morrissey JF. Colonoscopy in asymptomatic individuals with a family history of colorectal cancer. Arch Intern Med 1984;144:2209-11.

43. Chu KC, Tarone RE, Chow WH, et al. Temporal patterns in colorectal cancer: Incidence, survival and mortality from 1950 through 1990. J Natl Cancer Inst 1994;86:997-1006.

44. Giovannucci E, Ascherio A, Rimm EB, et al. Physical activity, obesity, and risk for colon cancer and adenoma in men. Ann Intern Med 1995;122:327-34.

45. Bayerdorffer E, Mannes GA, Ochsenkuhn T, et al. Increased risk of "high risk" colorectal adenomas in overweight men. Gastroenterology 1993;104:137-44.

46. Little J, Logan RF, Hawtin PG, et al. Colorectal adenomas and energy intake, body size and physical activity: A case-control study of subjects participating in the Nottingham faecal occult blood screening programme. $\mathrm{Br} \mathrm{J}$ Cancer 1993;67:172-6.

47. Stemmermann GN, Heilbrun LK, Nomura AY. Association of diet and other factors with adenomatous polyps of the large bowel: A prospective autopsy study. Am J Clin Nutr 1988; 47:312-7.

48. Bird CL, Frankl HD, Lee ER, et al. Obesity, weight gain, large weight changes, and adenomatous polyps of the left colon and rectum. Am J Epidemiol 1998;147:670-80. 


\begin{tabular}{|c|c|}
\hline Age (yr), mean (SD) & $57.9(8.6)$ \\
\hline Male sex, n (\%) & $1649(74.6)$ \\
\hline Body mass index $\left(\mathrm{kg} / \mathrm{m}^{2}\right)$, mean (SD) & $27.0(3.7)$ \\
\hline Cholesterol (mg/dl), mean (SD) & $230(41.4)$ \\
\hline Triglycerides (mg/dl), mean (SD) & $120(76.3)$ \\
\hline \multicolumn{2}{|l|}{ NSAIDs use, $\mathrm{n}(\%)$} \\
\hline No use & $2055(93.0)$ \\
\hline Use $<1 /$ day & $55(2.5)$ \\
\hline Use $\geq 1 /$ day & $82(3.7)$ \\
\hline \multicolumn{2}{|l|}{ Recruitment method, n (\%) } \\
\hline Routine health check-up & $1547(70.0)$ \\
\hline Follow-up of stable medical problems & $663(30.0)$ \\
\hline \multicolumn{2}{|l|}{ Nonspecific abdominal pain, ${ }^{*} \mathrm{n}(\%)$} \\
\hline No & $1109(50.2)$ \\
\hline Occasional $(<1 /$ day/wk $)$ & $577(26.1)$ \\
\hline Frequent ( $\geq 1 /$ day/wk) & $524(23.7)$ \\
\hline \multicolumn{2}{|l|}{ Bowel habit, n (\%) } \\
\hline Normal (1-2/day) & $1519(68.7)$ \\
\hline Chronic diarrhea-alternate & $142(6.5)$ \\
\hline Chronic constipation & $549(24.8)$ \\
\hline Good bowel preparation, n (\%) & $1229(55.6)$ \\
\hline \multicolumn{2}{|l|}{ Sedation, $\mathrm{n}(\%)$} \\
\hline No sedation & $426(19.3)$ \\
\hline Conscious sedation & $744(33.7)$ \\
\hline Deep sedation & $1013(45.8)$ \\
\hline \multicolumn{2}{|c|}{$\begin{array}{l}\text { NSAIDs = nonsteroidal anti-inflammatory drugs. } \\
* \text { Patients with persistent abdominal pain developed in } \\
\text { the year before colonoscopy were excluded from the } \\
\text { analysis. }\end{array}$} \\
\hline
\end{tabular}




\begin{tabular}{|c|c|}
\hline \multicolumn{2}{|c|}{$\begin{array}{l}\text { Table 2. Colonoscopic Findings According to } \\
\text { the Most Advanced Lesion }\end{array}$} \\
\hline Findings & n (\%) \\
\hline Total & $2210(100)$ \\
\hline No polyps & $1385(62.7)$ \\
\hline Patients with polyps & $825(37.3)$ \\
\hline Only miscellaneous findings* & $60(2.7)$ \\
\hline Only hyperplastic polyps & $87(3.9)$ \\
\hline Only fulgurated polyps\# & $61(2.8)$ \\
\hline Patients with any colonic adenoma or cancer & $617(27.9)$ \\
\hline \multicolumn{2}{|l|}{ Findings according to histologic type } \\
\hline Tubular adenoma & $516(23.3)$ \\
\hline$<10 \mathrm{~mm}$ & $462(20.9)$ \\
\hline$\geq 10 \mathrm{~mm}$ & $54(2.4)$ \\
\hline Villous adenoma & $90(4.0)$ \\
\hline$<10 \mathrm{~mm}$ & $32(1.4)$ \\
\hline$\geq 10 \mathrm{~mm}$ & $58(2.6)$ \\
\hline Patients with invasive cancer & $11(0.5)$ \\
\hline \multicolumn{2}{|l|}{ Findings according to grade of dysplasia } \\
\hline Mild dysplasia & $437(19.8)$ \\
\hline$<10 \mathrm{~mm}$ & $379(17.2)$ \\
\hline$\geq 10 \mathrm{~mm}$ & $58(2.6 \geq)$ \\
\hline Moderate dysplasia & $153(6.9)$ \\
\hline$<10 \mathrm{~mm}$ & $109(4.9)$ \\
\hline$\geq 10 \mathrm{~mm}$ & $44(2.0)$ \\
\hline Severe dysplasia_-cancer & $27(1.2)$ \\
\hline$<10 \mathrm{~mm}$ & $6(0.3)$ \\
\hline$\geq 10 \mathrm{~mm}$ & $21(0.9)$ \\
\hline \multicolumn{2}{|l|}{ Any advanced adenoma } \\
\hline Broad definition & $259(11.7)$ \\
\hline Restricted definition & $156(7.0)$ \\
\hline \multicolumn{2}{|c|}{$\begin{array}{l}\text { * Miscellaneous findings: normal mucosa, chronic nonspecific } \\
\text { inflammation, inflammatory or juvenile polyps, lymphoid } \\
\text { aggregates, lipomas. } \\
\text { \# In } 61 \text { patients, diminutive colonic polyps (always }<5 \mathrm{~mm} \text { ) } \\
\text { became totally fulgurated during resection with polypectomy } \\
\text { snare, and histology was not known. }\end{array}$} \\
\hline
\end{tabular}


Table 3. Prevalence and Location of Advanced Neoplasms in the Study Population $(\mathrm{N}=2210)$.

\begin{tabular}{|c|c|c|}
\hline \multirow{2}{*}{} & \multicolumn{2}{|c|}{$\mathrm{n}(\%)$} \\
\cline { 2 - 3 } & $\begin{array}{c}\text { Broad } \\
\text { Definition }\end{array}$ & $\begin{array}{c}\text { Restricted } \\
\text { Definition }\end{array}$ \\
\hline Location of Advanced Neoplasms & $259(11.7)$ & $156(7.0)$ \\
\hline Only in distal colon* & $137(52.9)$ & $100(64.1)$ \\
Only in proximal colon* & $68(26.3)$ & $37(23.7)$ \\
Both proximal and distal colon & $54(20.8)$ & $19(12.2)$ \\
\hline
\end{tabular}

* Adenomas were defined as distal if they came from the descending colon or more distally (in the sigmoid colon or rectum). Otherwise, the polyps were designated as proximal. 
Table 4. Comparative Characteristics of Patients Regarding the Presence and Kind of Colonic Adenomas.

\begin{tabular}{|c|c|c|c|c|}
\hline & $\begin{array}{l}\text { Absence of } \\
\text { Adenomas }\end{array}$ & $\begin{array}{c}\text { Only } \\
\text { Non-Advanced } \\
\text { Adenomas }\end{array}$ & $\begin{array}{c}\text { Advanced } \\
\text { Adenomas* }\end{array}$ & $p^{\#}$ \\
\hline Total & $1593(72.1)$ & $358(16.2)$ & $259(11.7)$ & \\
\hline \multicolumn{5}{|l|}{ Categoric variables } \\
\hline Sex & & & & $<0.001$ \\
\hline Male & $1124(68.2)$ & $303(18.4)$ & $222(13.5)$ & \\
\hline Female & $469(83.6)$ & $55(9.8)$ & $37(6.6)$ & \\
\hline NSAIDs daily & & & & 0.220 \\
\hline No & 1517 (71.9) & $342(16.2)$ & 251 (11.9) & \\
\hline Yes & $64(78.0)$ & $11(13.4)$ & $7(8.5)$ & \\
\hline Form of recruitment & & & & 0.882 \\
\hline Routine medical check-up & $1113(71.9)$ & $257(16.6)$ & 177 (11.4) & \\
\hline Other causes & $480(72.4)$ & $101(15.2)$ & $82(12.4)$ & \\
\hline Nonspecific abdominal pain & & & & 0.343 \\
\hline No & $787(71.0)$ & $187(16.9)$ & 135 (12.2) & \\
\hline Occasional & $425(73.7)$ & $85(14.7)$ & $67(11.6)$ & \\
\hline Frequent & $381(72.7)$ & $86(16.4)$ & $57(10.9)$ & \\
\hline Bowel habit & & & & 0.788 \\
\hline 1-2 movements/day & $1086(71.5)$ & $257(16.9)$ & $176(11.6)$ & \\
\hline Diarrhea-alternate & $109(76.8)$ & $16(11.3)$ & $17(12.0)$ & \\
\hline Chronic constipation & $398(72.5)$ & $85(15.5)$ & $66(12.0)$ & \\
\hline \multicolumn{5}{|l|}{ Continuous variables } \\
\hline Age (yr) & $57.2(8.6)$ & $58.8(8.4)$ & $61.2(8.5)$ & $\begin{array}{l}<0.001 \ddagger \\
0.001 \S\end{array}$ \\
\hline BMI $\left(\mathrm{kg} / \mathrm{m}^{2}\right)$ & $26.9(3.7)$ & $27.0(3.6)$ & $27.9(3.4)$ & $\begin{array}{l}0.005 \$ \\
0.015 \S\end{array}$ \\
\hline Cholesterol (mg/dl) & $228.3(41)$ & $233.7(40.8)$ & $236.6(44.0)$ & $\begin{array}{l}0.001 \$ \\
0.454 \S\end{array}$ \\
\hline Triglycerides (mg/dl) & $118.6(77.7)$ & $127.0(78.5)$ & $121.4(63.2)$ & $\begin{array}{l}0.155 \$ \\
0.395 \S\end{array}$ \\
\hline
\end{tabular}

Data are presented as $\mathrm{n}(\%)$ for categoric variables, mean (SD) for continuous variables.

* Advanced adenoma: any adenoma $\geq 1 \mathrm{~cm}$ and/or tubulovillous-villous and/or with moderatesevere dysplasia.

${ }^{*}$ Comparisons of categoric variables were established by $\chi^{2}$ test for linear trend. Comparisons of continuous variables were done with a priori contrasts in one-way ANOVA test.

\$ Compares persons without adenomas versus persons with any colonic adenoma.

$\S$ Compares persons with non-advanced adenomas versus persons with at least one advanced lesion. 


\begin{tabular}{|c|c|c|c|c|c|c|}
\hline \multirow[b]{2}{*}{ Variable } & \multicolumn{2}{|c|}{$\begin{array}{c}\% \text { Patients With } \\
\text { Advanced }\end{array}$} & \multicolumn{2}{|c|}{ Crude OR (95\% CI) } & \multicolumn{2}{|c|}{ Adjusted OR (95\% CI) } \\
\hline & $\begin{array}{c}\text { Mode } \\
\text { 1A }\end{array}$ & $\begin{array}{l}\text { Mode } \\
\text { 1B }\end{array}$ & Model A & Model B & Model A & Model B \\
\hline \multicolumn{7}{|l|}{ Age (yr) } \\
\hline$\leq 550$ & 5.4 & 3.1 & 1 & 1 & 1 & 1 \\
\hline $51-60$ & 10.6 & 6.1 & $2.07(1.3-3.3)$ & $2.01(1.1-3.7)$ & $1.82(1.1-3.0)$ & $1.98(1.0-3.8)$ \\
\hline $61-70$ & 14.9 & 9.2 & $3.06(1.9-4.8)$ & $3.12(1.7-5.6)$ & $2.49(1.5-4.1)$ & $2.84(1.5-5.5)$ \\
\hline$>70$ & 20.8 & 12.9 & $4.60(2.7-7.9)$ & $4.57(2.3-9.1)$ & $3.94(2.1-7.3)$ & $4.72(2.2-10.3)$ \\
\hline \multicolumn{7}{|l|}{ Sex } \\
\hline Female & 6.6 & 3.0 & 1 & 1 & 1 & 1 \\
\hline Male & 13.5 & 8.4 & $2.51(1.5-3.1)$ & $2.94(1.8-4.9)$ & $2.08(1.3-3.2)$ & $3.64(1.9-7.1)$ \\
\hline \multicolumn{7}{|c|}{ BMI $\left(\mathrm{kg} / \mathrm{m}^{2}\right)$} \\
\hline$\leq 25$ & 7.4 & 4.5 & 1 & 1 & 1 & 1 \\
\hline $26-30$ & 12.5 & 7.7 & $1.78(1.2-2.6)$ & $1.74(1.1-2.9)$ & $1.56(1.0-2.3)$ & $1.43(0.8-2.4)$ \\
\hline$>30$ & 16.1 & 9.5 & $2.39(1.5-3.8)$ & $2.20(1.2-3.9)$ & $2.08(1.3-3.3)$ & $1.78(1.0-3.2)$ \\
\hline
\end{tabular}




\begin{tabular}{|l|c|c|}
\hline \multicolumn{3}{|c|}{ Table 6. Estimation of the Score } \\
\hline Variable & Level & Score \\
\hline \multirow{2}{*}{ Sex } & Male & 2 \\
& Female & 0 \\
\hline \multirow{3}{*}{ BMI $\left(\mathrm{kg} / \mathrm{m}^{2}\right)$} & $\leq 25$ & 0 \\
& $25-35$ & 1 \\
& $>35$ & 2 \\
\hline \multirow{4}{*}{ Age $(\mathrm{yr})$} & $\leq 50$ & 0 \\
& $51-60$ & 1 \\
& $61-70$ & 2 \\
& $71-80$ & 3 \\
& $>80$ & 4 \\
\hline
\end{tabular}

Table 7. Diagnostic Yield of Colonoscopy for Advanced Adenomas

\begin{tabular}{|c|c|c|c|c|c|}
\hline \multirow[b]{2}{*}{ Score } & \multicolumn{2}{|c|}{$\begin{array}{c}\text { Advanced Colonic } \\
\text { Adenomas } \\
\text { (n) }\end{array}$} & \multirow[b]{2}{*}{$\begin{array}{c}\% \text { with advanced } \\
\text { adenomas }\end{array}$} & \multirow[b]{2}{*}{ PPV } & \multirow[b]{2}{*}{ NNS } \\
\hline & No & Yes & & & \\
\hline \multicolumn{6}{|c|}{ Broad definition for advanced colonic adenoma } \\
\hline 0 & 41 & 0 & 0 & 12.0 & 8.3 \\
\hline 1 & 109 & 8 & 7 & 12.4 & 8.1 \\
\hline 2 & 195 & 6 & 3 & 13.8 & 7.2 \\
\hline 3 & 371 & 37 & 9 & 15.9 & 6.3 \\
\hline 4 & 418 & 69 & 14 & 17.9 & 5.6 \\
\hline 5 & 299 & 60 & 17 & 23.4 & 4.3 \\
\hline 6 & 56 & 15 & 21 & 50.0 & 2.0 \\
\hline 7 & 3 & 3 & 50 & & \\
\hline \multicolumn{6}{|c|}{ Restricted definition for advanced colonic adenoma } \\
\hline 0 & 41 & 0 & 0 & 7.3 & 13.7 \\
\hline 1 & 116 & 1 & 1 & 7.8 & 12.9 \\
\hline 2 & 197 & 4 & 2 & 8.6 & 11.6 \\
\hline 3 & 388 & 20 & 5 & 10.3 & 9.7 \\
\hline 4 & 442 & 45 & 9 & 11.5 & 8.7 \\
\hline 5 & 322 & 37 & 10 & 16.7 & 6.0 \\
\hline 6 & 60 & 11 & 15 & 33.3 & 3.0 \\
\hline 7 & 4 & 2 & 33 & & \\
\hline \multicolumn{6}{|c|}{$\begin{array}{l}\text { NNS = number needed to screen (the number of patients who } \\
\text { would have to undergo colonoscopic screening to identify one } \\
\text { patient with at least one advanced neoplasm). } \\
\text { PPV = positive predictive value. }\end{array}$} \\
\hline
\end{tabular}

